Check for updates

The BMJ

Cite this as: $B M J 2022 ; 376: 0233$ http://dx.doi.org/10.1136/bmi.0233 Published: 27 January 2022

\section{Covid-19: Lower vaccination rates partly explain higher death rates among minority ethnic groups}

\author{
Ingrid Torjesen
}

Death rates from covid-19 remain higher for most minority ethnic groups compared with people identifying as white British, and some of that disparity is because of their lower uptake of vaccinations, show data from the Office for National Statistics (ONS).

Throughout the pandemic covid-19 mortality has been higher in most minority ethnic groups compared with white British people.

Vahé Nafilyan, senior statistician at the ONS, said, "As already highlighted in our analyses of earlier periods, these differences in mortality are largely explained by sociodemographic and economic factors and health. For the first time, we show that the lower vaccination coverage in some ethnic groups also contributes to the elevated risk of covid-19 death, particularly in the black African and black Caribbean groups."

While the risk of death from covid-19 was highest for people in the black African group during the first wave of the pandemic, the latest data show that between the start of the vaccination programme and the end of the second wave of the pandemic (8 December 2020 to 12 June 2021), covid-19 death rates were highest for the Bangladeshi group (5.0 times greater for males and 4.5 for females), followed by the Pakistani group (3.1 for males, 2.6 for females), and black African group (2.4 for males, 1.7 for females). Only Chinese people and women identifying as white other had similar levels of mortality to white British people.

Adjusting for factors such as geographical location, measures of disadvantage, occupation, living arrangements, and pre-existing health conditions substantially reduced excess covid-19 mortality risk for most ethnic groups, and after adjusting for vaccination status there was no evidence of greater risk of death from covid-19 in the black Caribbean group or in black African females.

Provisional data for the third wave of the pandemic (13 June to 1 December 2021) suggests that the risk of death remained highest for the Bangladeshi group (4.4 times greater for males and 5.2 times greater for females) compared with people identifying as white British, and that was followed by Pakistani (3.5 times greater for men, 4.3 for women), black Caribbean (2.3 for men, 3.0 for women), and black African (1.6 for men, 2.4 for women) groups. Again, people from black Caribbean and black African ethnic groups remained at higher risk of death than white British people after adjusting for demographic and socio-economic factors and pre-existing health conditions but not after adjusting for vaccination status, suggesting that differences in vaccination coverage explain a large part of the excess risk in these two groups.

The data for the third wave are provisional because they may not include all deaths and vaccinations and the third wave of the pandemic may not have ended.

Veena Raleigh, senior fellow at the King's Fund, said the figures highlighted "the complex relationship between ethnicity and the risk of dying from the virus."

"It is deeply concerning that vaccine uptake remains lowest in some communities with the highest risk of covid-19 mortality in all three waves-only about one third of Pakistani, black Caribbean, and black African adults, and less than half of Bangladeshi adults, have had three jabs. It's vital that services engage with said.

"Tackling the factors driving health inequalities and the disproportionate impact of the pandemic on poorer and ethnic minority communities should be a priority in the government's post-covid-19 recovery plans.”

\section{Office for National Statistics. Updating ethnic contrasts in deaths involving the coronavirus (covid-19), England: 8 December 2020 to 1 December 2021. 26 January 2022. www.ons.gov.uk/peoplepopulationandcommuni- ty/birthsdeathsandmarriages/deaths/articles/updatingethniccontrastsin- deathsinvolvingthecoronaviruscovid19englandandwales/8decem- ber2020to1december2021.}

This article is made freely available for personal use in accordance with BMJ's website terms and conditions for the duration of the covid-19 pandemic or until otherwise determined by BMJ. You may download and print the article for any lawful, non-commercial purpose (including text and data mining) provided that all copyright notices and trade marks are retained. these communities to improve vaccine uptake," she 